\title{
Curso de especialização em biotecnologia em saúde: análise e percepção de egressos
}

\section{Specialization course in healthcare biotechnology: analysis and perception of graduates}

\author{
${ }^{1}$ Flávia Coelho Ribeiro Mendonça \\ ${ }^{1}$ Marco Antônio Ferreira da Costa \\ ${ }^{2}$ Maria Beatriz Siqueira Campos de Oliveira \\ ${ }^{1}$ Mônica Mendes Caminha Murito
}

\section{RESUMO}

Os laboratórios que trabalham com desenvolvimento tecnológico convivem com o desafio de que as novas tecnologias apontam, cada vez mais, para a especialização. Desta forma, cada atividade desempenhada possui um conjunto de conhecimentos que se articulam, tornando o trabalho altamente complexo, de tal forma que aquele trabalhador configura-se em um especialista naquele setor. O objetivo deste artigo foi analisar as características curriculares e percepções dos egressos do curso de Especialização Técnica em Biotecnologia em Saúde que teve inicio no Instituto de Tecnologias em Imunobiológicos (Bio-Manguinhos) / Fiocruz, no ano de 2004, e que, posteriormente, passou a ser ministrado pela Escola Politécnica de Saúde Joaquim Venâncio. A relevância deste estudo está no fato de que os seus resultados poderão contribuir para a reformulação e aprimoramento do currículo do curso investigado, além de fundamentar estudos curriculares por outras escolas técnicas. Foi realizada uma pesquisa descritiva-documental, com abordagem qualitativa, e teve como sujeitos os coordenadores do curso e os alunos formados nas turmas de 2004 a 2008. Foram utilizados como instrumento de coleta, questionários e entrevistas. A análise das características curriculares e das percepções dos egressos do curso de Especialização Técnica em Biotecnologia em Saúde apontaram a importância de se manter este curso. No entanto, um dos desafios seria a necessidade de se adequar às limitações de formação básica dos profissionais técnicos que trabalham nessa área e que precisam ter o conhecimento teórico para embasar as práticas que já realizam rotineiramente.

Palavras-chave: Educação profissional; Currículo; Biotecnologia em Saúde.

1 Escola Politécnica de Saúde Joaquim Venâncio/ Fiocruz

2 Instituto Nacional da Saúde da Criança da Mulher e do Adolescente Fernandes Figueira IFF/ Fiocruz 


\section{ABSTRACT}

Laboratories that works with technological development deals with the challenge that new technologies points, increasingly, to the specialization. Thus, each activity performed has a set of skills that articulates one with each other, turning the activity such complex that the worker become an expert in that sector. The goal of this paper was to analyze the curriculum and perceptions characteristics of students graduated from Technical Specialization Healthcare Biotechnology Course, which began at the Institute of Technology in Immunobiology (Bio-Manguinhos)/ Fiocruz, in 2004, and subsequently passed to be ministered by the Polytechnic School of Health Joaquim Venâncio. The relevance of this study is in the fact that it's results might contribute to the redesign and improvement of the investigated course's curriculum, besides support curriculum studies by other technical schools. A descriptive and documentary research with a qualitative approach was performed and had as subjects the course's coordinators and the graduated students in the classes of 2004 to 2008. Questionnaires and interviews were the tools used for data collection. The analysis of curriculum features and perceptions of the students who had graduate from Technical Expertise in Biotechnology Health pointed out the importance of keeping this course. However, one of the challenges would be the need of adaptation to the limitations of the basic training of technical professionals that works in this area that needs to have the theoretical knowledge to support practices that already perform routinely.

Keywords: Profession education; Curriculum; Biotechnology in Health.

\section{INTRODUÇÃO}

A Escola Politécnica de Saúde Joaquim Venâncio (EPSJV), é uma Unidade Técnico-Científica da Fundação Oswaldo Cruz, responsável pela coordenação e execução das atividades de ensino e pesquisa na área de Educação Profissional em Saúde. Além disso, mantém cooperação nacional e internacional com outras instituições, tendo como foco a formação do trabalhador técnico em Saúde. Uma das ações concretas da EPSJV neste campo é o Curso de Especialização Técnica em Biotecnologia em Saúde. Este curso foi implantado no ano de 2004, e teve como origem o curso técnico oferecido pelo Instituto de Tecnologias em Imunobiológicos (Bio-Manguinhos) para os técnicos de laboratório daquela Unidade da Fundação Oswaldo Cruz.

Os Cursos de Especialização Técnica são o aprofundamento de estudos ou a complementação de uma Habilitação Técnica de Nível Médio, estando a ela obrigatoriamente vinculada, nos termos da Resolução CNE/ CEB nº 04/99, do Parecer CNE/CEB n ${ }^{\circ}$ 16/99 e do Parecer CNE/CEB nº 14/02; devendo propiciar o domínio de novas competências àqueles que já são habilitados e que desejam especializar-se em um determinado segmento profissional. Ao se buscar uma análise das trajetórias profissionais dos ex-alunos do Curso de Especialização Técnica em Biotecnologia em Saúde foi importante investigar, também, como as mudanças introduzidas pelas políticas educacionais influenciaram na formação técnica e como os egressos se posicionaram frente às rápidas transformações tecnológicas e científicas relacionados aos processos produtivos.

As mudanças ocorridas no mundo do trabalho apontam para uma nova forma de relação entre ciência e trabalho, na qual as formas de fazer, determinadas atividades com base em processos técnicos simplificados, restritos geralmente a uma área do conhecimento, portanto, facilmente identificáveis e estáveis, passam a ser substituídas por ações que articulem conhecimento científico, capacidades cognitivas superiores e capacidade de intervenção crítica e criativa perante situações não previstas. Estas ocorrências exigem soluções rápidas, origi- 
nais e teoricamente fundamentadas, para responder ao caráter dinâmico, complexo, interdisciplinar e opaco que caracteriza a tecnologia na contemporaneidade (KUENZER, 2000).

Ao técnico de escolaridade média, era imposta uma atuação definida pelo taylorismo na intermediação da concepção à execução, agora com a fábrica global se contempla não só a interação produtor e cliente, mas também o trabalho em equipe. A horizontalização produtiva, com eliminação de funções intermediárias pela integração e flexibilização de tarefas, exige capacitação diferenciada do técnico, a partir de saber-fazer-técnico e de saber-fazer-relacional no trato de questões originadas não somente da fabricação, mas dos setores de compras, de marketing, do comercial, como da engenharia de produto e de processos (LAUDARES e TOMASI, 2003).

Na saúde, a biotecnologia pode ser aplicada à produção de medicamentos derivados de plantas (fitoterápicos), produção de vacinas, soros antiofídicos, imunobiológicos, entre outros. Um grande avanço nessa área ocorreu em 1928 com a descoberta do antibiótico, por Alexander Fleming, o qual delimita o crescimento microbiano. Outro avanço foi o emprego de organismos vivos para a síntese de moléculas complexas, como por exemplo, a bradicinina, um medicamento que controla a hipertensão, que foi desenvolvida por pesquisadores brasileiros no Departamento de Bioquímica e Farmacologia da Faculdade de Medicina de Ribeirão Preto-USP em 1948 (LIMA, 2007). E ainda, nas três últimas décadas do século XX a biotecnologia conquistou avanços com o desenvolvimento de técnicas que possibilitaram a manipulação de genes, como no caso da Engenharia Genética (AZEVEDO et al., 2002). Segundo Raw (2007), o estudo nesta área é considerado um importante instrumento para o desenvolvimento do país.

Garcia (1995) aponta que a biotecnologia aplicada a saúde, compreendida em toda a sua abrangência, está relacionada com qualquer exploração tecnológica da biodiversidade para resolver problemas de saúde do homem. Na visão de Raw (2007), o Brasil precisa de uma elite inovadora que domine a biologia molecular, química orgânica sintética, bioquímica, farmacologia, cristalografia e modelagem química, processos industriais de fermentação e síntese, trabalhando em equipe a fim de criar novas tecnologias e produtos, de maneira a reduzir custo para a produção industrial e ser considerado uma nação desenvolvida nessa área.

Os laboratórios que trabalham com desenvolvimento tecnológico convivem com o desafio de que as novas tecnologias apontam cada vez mais para a especialização, no âmbito de que cada atividade desempenhada possui um conjunto de conhecimentos que se articulam, tornando o trabalho altamente complexo, de tal forma que aquele trabalhador configure-se um especialista naquele setor. Entretanto, é fundamental destacar que atividade técnica implica em conhecimento geral, desse modo a especialização não significa que os trabalhadores não tenham conhecimento processual do trabalho ali realizado e dos saberes necessários para executá-lo.

Nesses cenários, e considerando que a biotecnologia, no quadro das transformações tecnológicas na área da saúde, supera o currículo do curso técnico, que sozinho não consegue dar conta da base científica que embasa as tecnologias de ponta desta área, foi planejado, a partir do decreto n 5154/04 do MEC, o curso de Especialização Técnica em Biotecnologia em Saúde, nosso objeto de estudo, focado especialmente na área de imunobiológicos, tendo como base a educação politécnica.

É importante ressaltar, que a proposta curricular da Escola Politécnica de Saúde Joaquim Venâncio se fundamenta dentro dos princípios político-pedagógicos de uma concepção politécnica, em que a formação profissional implica na compreensão da totalidade e dos fundamentos técnicos e científicos do mundo trabalho, estando assim os profissionais aptos a intervir na realidade sócio-técnica.

Portanto, este artigo teve como objetivo analisar as características curriculares do curso e percepções de egressos do Curso de Especialização Técnica em Biotecnologia em Saúde, oferecido pela Escola Politécnica de Saúde Joaquim Venâncio (EPSJV) no período de 2004 a 2008, analisando elementos do currículo, como disciplinas oferecidas, carga horária, conteúdos, relações com o mercado de trabalho, entre outros, no sentido de permitir uma análise crítica que possibilite a reformulação e aprimoramento do seu currículo. Segundo Meira e 
Kurcgant (2009), avaliar os cursos, através das percepções dos egressos possibilita analisar as transformações que ocorreram nestes alunos, em consequência principalmente, da influencia exercida pelos currículos destes cursos. Schawartzman e Castro (1991) corroboram com essas ideias ao concluir que os resultados da percepção de egressos recupera, de fato, várias questões do estudo de alunos, particularmente as ligadas: à qualidade do ensino e adequação dos currículos à situação profissional; à origem dos projetos profissionais e a sua consistência em relação à situação profissional de fato.

\section{DESENHO METODOLÓGICO}

Foi realizada uma pesquisa descritiva-documental, apoiada no paradigma qualitativo (MINAYO, 2012). Os sujeitos da pesquisa foram todos os alunos formados no período de 2004 a 2008, totalizando 35 egressos, sendo 12 da turma de 2004, 12 da turma de 2006 e 11 da turma de 2008. Todos foram contatados via e-mail ou por telefone, de acordo com os dados obtidos no cadastro de inscrição dos alunos no curso, na secretaria escolar da EPSJV. Além disto, foram entrevistados os coordenadores do curso para o período de 2004 a 2008.

Dentre esses 35 egressos, cinco da turma de 2004, um da turma de 2006 e três da turma de 2008 concordaram em participar da pesquisa, somando-se, portanto, nove pessoas que enviaram questionários respondidos. Para a coleta dos dados desses egressos, foram empregados questionários semi-estruturados com perguntas abertas e fechadas. Esse instrumento de coleta foi enviado por email. Os dados foram analisados no contexto multirreferencial (ARDUÍNO, 1998), à luz do referencial teórico adotado. Foi utilizada a interpretação simples da análise das falas dos sujeitos (MYERS, 2004). Não tivemos a intenção, no momento, de realizar uma avaliação do curso em pauta, mas sim, como explicitado no objetivo, analisar as características curriculares e percepções de egressos e também tecer algumas considerações sobre o curso. Para essa pesquisa foi mantido o anonimato dos sujeitos, nomeando-os como "E” de egressos, seguido do número do questionário respondido.

O estudo foi aprovado pelo Comitê de Ética em Pesquisa com Seres Humanos (CEP) da EPSJV, sob o número 2011/ 0135.

\section{RESULTADOS E DISCUSSÃO}

O curso de Especialização Técnica em Biotecnologia em Saúde da EPSJV teve como origem o curso técnico oferecido pelo Instituto de Tecnologias em Imunobiológicos (Bio-Manguinhos) em 2004, para os técnicos de laboratório daquela Unidade da Fundação Oswaldo Cruz.

O curso objetiva formar técnicos especialistas em Biotecnologia em saúde para que permita uma qualificação profissional que permitisse ao egresso atuar em setores da saúde na área de imunobiológicos, tais como: produção e controle da qualidade, pesquisa e desenvolvimento de vacinas e kits para diagnósticos e biofármacos. Essa formação era destinada a trabalhadores que tivessem concluído o ensino médio que exerciam funções nas áreas da biotecnologia em saúde há pelo menos um ano e aos egressos do curso de Biodiagnóstico da EPSJV, posteriormente, denominado Análises Clínicas.

Foram realizadas três edições nos anos de 2004, 2006 e 2008, uma em cada ano. A estrutura básica inicial nas turmas de 2004 e de 2006 dividia-se em três módulos: 1) Módulo Básico, com 310 horas e 11 disciplinas; 2) Módulo de Bioprocessos e Suporte Biotecnológico, com 155 horas e oito disciplinas e 3) Módulo de Relações Profissionais, com 175 horas e também oito disciplinas, totalizando uma carga horária total de 640 horas de curso. Posteriormente, na turma de 2008, a estrutura do curso continuou sendo a mesma, dividida em três módulos, entretanto, aumentou-se a carga horária das disciplinas, levando, consequentemente, a uma carga horária maior dos módulos, passando o módulo I para 489 horas, o módulo II para 279 e o módulo III para 207, somando-se um total de 975 horas. 
A coordenadora do curso nas três edições, sobre a alteração da carga horária, afirmou que:

deveu-se à solicitação dos docentes sobre a necessidade de acertar as disciplinas que estavam com carga horária insuficiente para os conteúdos ministrados, e também, para incluir aulas práticas, além de ajustar os horários "quebrados de aula”.

No Quadro 1 apresentamos os respectivos módulos com as disciplinas correspondentes.

Quadro 1- Módulos do Curso de Especialização Técnica em Biotecnologia em Saúde e respectivas disciplinas (2004 - 2006 e 2008)

\begin{tabular}{|c|c|c|c|}
\hline Módulo 1 - Básico & Horas aula - 2004 & Horas aula - 2006 & Horas aula - 2008 \\
\hline Matemática & 25 & 25 & 45 \\
\hline Física & 25 & 25 & 60 \\
\hline Química & 60 & 60 & 120 \\
\hline Biologia celular & 18 & 18 & 30 \\
\hline Bioquímica & 30 & 30 & 45 \\
\hline Bacteriologia Geral & 40 & 40 & 36 \\
\hline Imunologia Geral & 25 & 25 & 30 \\
\hline Microbiologia Médica & 17,5 & 17,5 & 18 \\
\hline Virologia & 27,5 & 27,5 & 45 \\
\hline Micologia & 17,5 & 17,5 & 30 \\
\hline Parasitologia & 17,5 & 17,5 & 30 \\
\hline TOTAL & 310 & 310 & 489 \\
\hline \multicolumn{4}{|c|}{ Módulo 2-Bioprocessos e Suporte Biotecnológico } \\
\hline Genética Bacteriana & 17,5 & 17,5 & 60 \\
\hline Biologia Molecular & 25 & 25 & 30 \\
\hline Fermentação & 17,5 & 17,5 & 45 \\
\hline Cultura de Células & 25 & 25 & 45 \\
\hline Produção e Purificação de Proteínas & 17,5 & 17,5 & 45 \\
\hline Manejo de Animais de Experimentação & 17,5 & 17,5 & 18 \\
\hline Produção e Purificação de Águas & 17,5 & 17,5 & 18 \\
\hline Operação, Envase e Liofilização & 17,5 & 17,5 & 18 \\
\hline TOTAL & 155 & 155 & 279 \\
\hline \multicolumn{4}{|l|}{ Módulo 3 - Relações Profissionais } \\
\hline Gestão da Qualidade & 25 & 25 & 30 \\
\hline Biossegurança & 12,5 & 12,5 & 15 \\
\hline Propriedade Intelectual & 12,5 & 12,5 & 15 \\
\hline Informática & 22,5 & 22,5 & 21 \\
\hline Bioinformática & 12,5 & 12,5 & 21 \\
\hline Relações Humanas & 12,5 & 12,5 & 15 \\
\hline Processo de Trabalho em Saúde & 17,5 & 17,5 & 30 \\
\hline Prática Profissional & 60 & 60 & 60 \\
\hline TOTAL & 175 & 175 & 207 \\
\hline TOTAL DE HORAS & 640 & 640 & 975 \\
\hline
\end{tabular}


Na turma de 2004 a 2005, todos os 20 alunos matriculados foram aprovados. Na turma de 2006 a 2007, dos 20 alunos matriculados, 14 foram aprovados, sendo que dentre esses, 3 refizeram o curso em 2008, por isso foram considerados aprovados. Na turma de 2008 a 2009, foram matriculados 29 alunos, sendo que 11 foram reprovados e 4 desistentes (o setor onde eles atuavam não os liberaram). É importante destacar, que apenas 10\% do total de alunos matriculados nas três turmas (69) não trabalhavam na época, apenas estudavam. Segundo Siqueira (2011), jovens que trabalham e estudam fazem um esforço demasiado, motivados pela esperança de crescimento profissional, mas que acaba sendo uma aventura, visto que precisam conciliar as horas de trabalho que permitem ganhar salário, com o trabalho de estudar que lhes exige tempo e dedicação. O tempo precisa ser dividido entre duas tarefas com dificuldades intrínsecas relativas a estes processos. Nas três turmas observamos colocações referentes ao trabalho desenvolvido em Biomanguinhos, quanto ao tempo presencial exigido pelo responsável do setor e pela própria atividade desenvolvida que demanda dedicação por parte do funcionário.

Na turma de 2008 a 2009 o maior índice de reprovação ocorreu no módulo 1 (básico). Isso ocorreu devido à falta de base dos alunos nas disciplinas básicas ministradas: matemática (três alunos), virologia (dois alunos), bacteriologia (um aluno), biologia celular (um aluno), física (um aluno), química (um aluno). Segundo Ciavata (2005) é importante que a educação geral se torne parte inseparável da educação profissional, ou seja, formar um trabalhador é compreender a necessidade de que algumas disciplinas são pré-requisitos para o entendimento de fenômenos estudados em diferentes áreas do conhecimento, desta forma, a química, a física, a matemática e a biologia são alicerces para a biologia celular e a bacteriologia. Outros pontos a serem destacados são o tempo que o aluno está afastado da escola e a maneira que aquele conhecimento foi introduzido. Escolas que privilegiam o aprendizado através da memorização acabam produzindo conhecimentos de curto prazo. Os alunos precisam compreender os processos e articulá-los com os fenômenos que vão sendo trabalhados nas disciplinas que precisam de um nível de compreensão maior.

As disciplinas do módulo 2 que reprovaram foram: biologia molecular (dois alunos), Fermentação (um aluno), cultura de célula (um aluno). Nessa turma (2008 a 2009), o módulo 3 (Relações profissionais) foi ministrado antes, devido a disponibilidade dos professores e a dificuldade que os alunos estavam apresentando em realizar o Trabalho de Final de Curso (TCC). Dessa forma, aulas de metodologia foram ministradas logo no início do curso visando dar condições aos alunos de selecionar o tema, fazer o recorte metodológico e definir o objetivo para elaborar a monografia (TCC) dentro do prazo estabelecido (2 anos).

Ao, ser questionada sobre o término do curso de 2008, a coordenadora respondeu que:

A interrupção do curso ocorreu para uma possível reformulação de modo que o módulo básico fosse retirado e substituído por uma prova de nivelamento para o ingresso no curso.

Segundo ainda a coordenadora:

O nível dos alunos caía gradativamente a cada ano em que o curso era oferecido, pois os matriculados eram cada vez mais jovens e não servidores (terceirizados).

Com relação à terceirização e suas relações com a organização do trabalho, cabe tecer alguns comentários. Uma das características do modelo fordista era a estabilidade e a solidez presentes na estrutura profissional, no qual a qualificação estava relacionada ao posto de trabalho e identificada como um estoque de conhecimentos formais, específicos e rígidos, conferidos pelo diploma (RAMOS, 2001). A literatura especializada indica o surgimento de uma nova lógica que desequilibra o modelo da "estabilidade do posto de trabalho". A partir das mudanças de base técnica e organizacional, com a influência do modelo japonês (toyotismo) tem-se uma nova lógica que passa a valorizar a experiência, a aprendizagem na atividade e o trabalho em equipe, contribuindo para o aumento do desencontro entre titulação e ocupação. Uma das características dos alunos trabalhadores deste curso é que a maioria foi formada no serviço, que prioriza, em forma geral, mais a prática do que a formação 
teórica. Este foi um problema que justificou a reprovação, especialmente no módulo básico, onde os fundamentos e conceitos que embasam as práticas foram abordados.

\section{O perfil dos egressos}

Trinta e cinco egressos foram contatados por e-mail ou por telefone. Dos nove egressos pesquisados, três pertencem ao sexo feminino e seis ao masculino e a idade atual dos egressos variou de 28 a 52 anos. O questionário possibilitou constatar que seis já haviam concluído o nível superior nas áreas de ciências biológicas ou de química, mas que três possuem ainda o nível médio. Dentre esses que ainda não têm o nível superior, um está cursando na área da saúde, um em outra área e apenas um não está fazendo a graduação. Atualmente, todos estão trabalhando na área da saúde, sendo cinco em cargos de técnico de nível médio e quatro em cargos de tecnologistas de nível superior. Dentre esses, apenas um egresso não participou de congressos, cursos ou seminários, os outros participam desses eventos em suas áreas para a atualização dos conteúdos requeridos pelo trabalho.

\section{Percepções dos egressos sobre o curso}

Foi relatado por todos os integrantes da pesquisa que os conhecimentos adquiridos no curso de especialização técnica em biotecnologia em saúde da EPSJV foram suficientes para a atuação profissional. Durante o curso, todos os egressos pesquisados estavam trabalhando e apesar de terem relatado que o processo de ensino-aprendizagem foi excelente (para sete egressos) ou muito bom (para dois), os egressos apresentaram sugestões para a melhoria da qualidade do curso, como, por exemplo, E4, apontou que:

Que seria interessante incluir novas técnicas e tecnologias como novas vacinas e biofármacos, que estão sendo desenvolvidos para a saúde brasileira.

Outro egresso (E8) acha que poderiam ser incluídas as disciplinas: genética clássica, noções de gerenciamento de indústrias de saúde, contabilidade e estatística. Para E9, a inclusão da disciplina biologia molecular forense seria interessante. É possível verificar que o egressos reconhece a importância desses conteúdos como uma forma de compreender seu processo de trabalho numa dimensão mais ampla, que vai além da dimensão técnica.

De acordo com as falas de egressos das turmas de 2004 e 2006, antes da mudança da carga horária do curso em que houve um aumento significativo no número de horas das disciplinas, ficou clara a necessidade do aumento da carga horária das disciplinas teóricas e práticas, como citou E3:

Seria muito importante aumentar a carga horária de algumas disciplinas, pois ficou bastante difícil para alguns professores repassarem todo conteúdo necessário, poderia aumentar o número de aulas práticas.

Conforme E6, “deveriam ser dadas mais aulas práticas relacionadas aos conteúdos abordados em sala de aula”. Essa foi uma das causas para a coordenação do curso, à época, aumentar a carga horária do curso.

Foi relatado pelos egressos que o curso muito contribuiu na sua formação:

Os conhecimentos do curso me facilitaram a compreensão de todo o processo de desenvolvimento de uma vacina (E9).

Me ajudou a sanar minha deficiência na área biológica (E4).

Acrescentou mais conhecimentos na área que realizo (E2).

Ampliação dos conhecimentos e repasse das informações (E3).

Abriu oportunidades de novas alternativas de trabalhos (E4). 
A maioria dos entrevistados considera que o curso contribuiu para ampliar seus conhecimentos e compreender melhor seu processo de trabalho, facilitando sua atuação na área profissional. Alguns apontam para abertura de novas oportunidades de trabalho e falam da importância do repasse de informações para consolidar os conhecimentos teóricos adquiridos durante esse curso.

Em pesquisa realizada no Google Acadêmico e na base Scielo, com os descritores, "avaliação, curso técnico biotecnologia saúde”, não foram encontrados artigos sobre esta temática, o que reforça, sobremaneira, a importância deste estudo, para tal modalidade de ensino.

\section{CONSIDERAÇÕES FINAIS}

O curso procurou, ao longo das suas edições, proporcionar desde o estabelecimento dos conhecimentos fundamentais da Biologia até o discernimento sobre as bases da Biotecnologia moderna e um senso crítico e responsável sobre temas complexos atuais, como a Bioética e Biossegurança. Os resultados mostraram que na turma de 2006, os egressos apresentavam muita deficiência na base teórica, por isso não conseguiam acompanhar nem as disciplinas consideradas básicas, como matemática, química e física daí o alto índice de reprovação, o que levou a EPSJV a aumentar, na turma de 2008, a carga horária do curso perfazendo um total de 970 horas, quase a carga horária necessária para um curso de habilitação.

Um ponto destacado por todos os alunos foi que o curso de Especialização Técnica em Biotecnologia em Saúde contribuiu, em muito, para a formação profissional destes alunos. Entretanto, o alto índice de reprovação da última turma composta, principalmente, por jovens profissionais, nos levou a concluir que as disciplinas elencadas com suas respectivas carga horárias são fundamentais para a formação deste profissional, mas o formato do curso precisa ser repensado. Existem duas possibilidades: a primeira seria ampliar a carga horária das disciplinas de 970 horas para 1200 horas, transformando-o em um curso de habilitação técnica, subsubsequente ou integrado; a segunda seria modificar o acesso ao curso, por meio de uma prova de nivelamento, em que selecionaria os alunos que já possuem um conhecimento prévio das disciplinas do módulo I (básico). Vale a pena ressaltar que esta última, excluiria os técnicos que já estão atuando nos laboratórios, que não tiveram oportunidade de estudar em um curso técnico formal, fazendo apenas o ensino médio, aprendendo as técnicas laboratoriais no serviço e os que fizeram curso técnico em outras áreas do conhecimento, que não seja a área biomédica.

A análise das percepções dos egressos do curso de Especialização Técnica em Biotecnologia em Saúde, apontou a importância de se manter um curso nessa área. No entanto, um dos desafios seria a necessidade de se adequar às limitações de formação básica dos profissionais técnicos que trabalham nessa área e que precisam ter o conhecimento teórico para embasar as práticas que já realizam rotineiramente, constatando-se que o processo de qualificação para o trabalho não se esgota na manipulação de equipamentos, pois o trabalho tem uma dimensão que compreende uma formação muito mais ampla, que não se restringe a capacitação tecnológica.

Finalizando, entendemos que este estudo, pelo seu caráter pragmático nos oportunizou a possibilidade de compreender as imbricações que perpassam pelo curso analisado, tais como, formação, currículo, perfil dos alunos e a aplicabilidade dos conhecimentos obtidos. Dessa forma, os resultados desta pesquisa podem fundamentar estudos curriculares, não apenas na EPSJV, como também em outras escolas técnicas. 


\section{REFERÊNCIAS}

ARDUÍNO, J. Abordagem multirreferencial (plural) das situações educativas e formativas. In: Barbosa JG, (Coord.). Multirreferencialidade nas ciências e na educação. São Carlos: UFSCAR; 1998.

AZEVEDO, N.; FERREIRA, L.O.; KROPF, S.P.; HAMILTON, W.S. Pesquisa científica e inovação tecnológica: a via brasileira da biotecnologia. Revista de Ciências Sociais, Rio de Janeiro, v.45, n.1, p.139-176. 2002.

BRASIL. Ministério da Educação.Secretaria de Educação Profissional e Tecnológica. Decreto nº 5.154, Brasília, 2004.

BRASIL. Ministério da Educação. Parecer CNE/CEB 14. Diretrizes Curriculares Nacionais para a Educação Profissional de Nível Técnico. Brasília, 2002.

BRASIL. Ministério da Educação. Parecer CNE/CEB 16. Diretrizes Curriculares Nacionais para a Educação Profissional de Nível Técnico. Brasília, 1999.

BRASIL. Ministério da Educação. Resolução CNE/CEB 04. Referenciais Curriculares Nacionais da Educação Profissional de Nível Técnico. Brasília; 1999.

CIAVATA, M. A formação integrada: a escola e o trabalho como lugares de memória e de identidade. In: Frigotto, G.; Ciavatta, M.; Ramos, M. Ensino Médio Integrado: Concepção e contradições. São Paulo: Cortez, 2005.

GARCIA, E. S. Biodiversidade, Biotecnologia e Saúde. Cadernos de Saúde Pública. Rio de Janeiro, 11 (3): 495-500, Jul/Sep, 1995.

KUENZER, A.Z. O Ensino Médio agora é para a vida: entre o pretendido, o dito e o feito. Educação \& Sociedade, ano XXI, n. 70, abril de 2000: 15-39.

LAUDARES, J.B.; TOMASI, A. O técnico de escolaridade média no setor produtivo: seu novo lugar e suas competências. Educação \& Sociedade, Campinas, vol. 24, n. 85, dez. de 2003, p. 1237-1256.

LIMA, L.M. Química Medicinal Moderna: desafios e contribuição brasileira. Revista Química Nova, vol.30 no.6 São Paulo Nov./Dec. 2007.

MEIRA, M.D.D; KURCGANT, P. Avaliação de curso de graduação segundo egressos. Escola de Enfermagem da USP, 2009; 43 (2): 481-5.

MINAYO, M.C.S. O Desafio do Conhecimento - pesquisa qualitativa em saúde. São Paulo: Ed. Hucitec, 2012.

MYERS, G. Análise da conversação e da fala. In: BAUER, M.W.; GASKELL, G. Pesquisa Qualitativa com Texto, Imagem e Som. $3^{\text {a }}$ edição. Petrópolis: Vozes, 2004.

RAMOS, M. N. A Pedagogia das Competências: autonomia ou adaptação? São Paulo: Cortez; 2001.

RAW, I. Biotecnologia e Saúde Pública. Revista USP, São Paulo, n.75, p. 6-17, setembro/novembro 2007.

SCHAWARTZMAN, S. CASTRO, M.H.M. A trajetória acadêmica e profissional dos alunos da USP. Documento de trabalho 2/91. São Paulo; Núcleo de Pesquisas sobre o ensino superior da Universidade de São Paulo, 1991.

SIQUEIRA, J., T., F. Trabalhar para estudar/ Estudar para trabalhar: Realidade e Possibilidades. V Encontro Brasileiro de Educação e Marxismo, Educação e Emancipação Humana- UFSC - Florianópolis - SC Brasil, 2011. 